\title{
Parallel Connected High Frequency AC Link Inverters Based on Full Digital Control
}

\author{
Deshang Sha ${ }^{\dagger}$, Zhiqiang Guo ${ }^{*}$, Kai Deng ${ }^{* *}$, and Xiaozhong Liao ${ }^{*}$ \\ ${ }^{\dagger *}$ School of Automation, Beijing Institute of Technology, Beijing, China \\ ${ }^{* *}$ School of Electrical Engineering, Southeast University, Nanjing, China
}

\begin{abstract}
This paper presents a full digital control strategy for parallel connected modular inverter systems. Each modular inverter is a high frequency (HF) AC link inverter which is composed of a HF inverter and a HF transformer followed by a cycloconverter. To achieve equal sharing of the load current and to suppress the circulating currents among the modules, a three-loop control strategy, consisting of a common output voltage regulation (OVR) loop, individual circulating current suppression (CCS) loops and individual inner current tracking (ICT) loops, is proposed. The ICT loops are implemented with predictive current control from which high precision current tracking can be obtained. The effectiveness of the proposed control strategy is verified by simulation and experimental results from parallel connected two full-bridge HF AC link inverter modules.
\end{abstract}

Key words: Digital control, Current sharing, High frequency AC link inverters, Parallel connection, Predictive control current, Phase-shifted PWM

\section{INTRODUCTION}

Parallel connected modular inverters are a more reliable and economic solution for many applications such as UPS and distributed renewable power distribution and generation systems[1], [2]. Modularized inverters can share a high load current and with this configuration small power rating switches can be used in high power applications. In addition, this system features redundancy, uninterrupted operation capability and high reliability.

Concerning the topology of each constituent module, the most widely used is a high frequency isolated dc/dc converter in series with a dc/ac inverter [3]-[5]. However, this kind of configuration is applicable only when the active power flow is unidirectional. Another disadvantage is that the conversion efficiency of the whole system is limited due to the three stages of the power conversion. In addition, the DC-DC converter and DC-AC inverter need individual systems, which complicates the whole control system design. HF AC link inverters have positive attributes such as the elimination

Manuscript received Sep. 14, 2010; revised Jun. 5, 2012

Recommended for publication by Associate Editor Han-Ju Cha.

${ }^{\dagger}$ Corresponding Author: shadeshang@bit.edu.cn

Tel: +86-10-68918613, Beijing Institute of Technology

* School of Automation, Beijing Institute of Technology, China

${ }^{* *}$ School of Electrical Engineering, Southeast University, China of bulky capacitors and bi-directional power flow capability without adding additional components, which improve the conversion efficiency and reliability [6]-[8]. This has been discussed extensively in the literature. However, parallel connected HF AC link inverters are seldom discussed.

The control of parallel connected inverters is difficult because the individual output voltages should have the same frequency, phase, and amplitude for ideal operations [9], otherwise circulating currents can be generated. To make the system work properly, several control strategies have been proposed. Despite the fact that the interconnection between modules is eliminated with the frequency/voltage droop control, the load current sharing capability varies with different loads [1], [10]. If the master module fails with the mast-slave control strategy, the whole system fails [11]. The central control strategy is widely used. The current weighting distribution control strategy can achieve current sharing among the constituent modules, but the currents flowing through the filtering capacitors have to be sensed as well as those through the output inductor currents. With the uniform modulation control strategy, despite the fact that there are no circulating currents, both the modulation and carrier waveforms should have the same frequency, phase, and amplitude [9]. Additionally, it is effective only for inverter modules with well-matched parameters including the same DC input voltage for the individual DC-AC inverters. An 


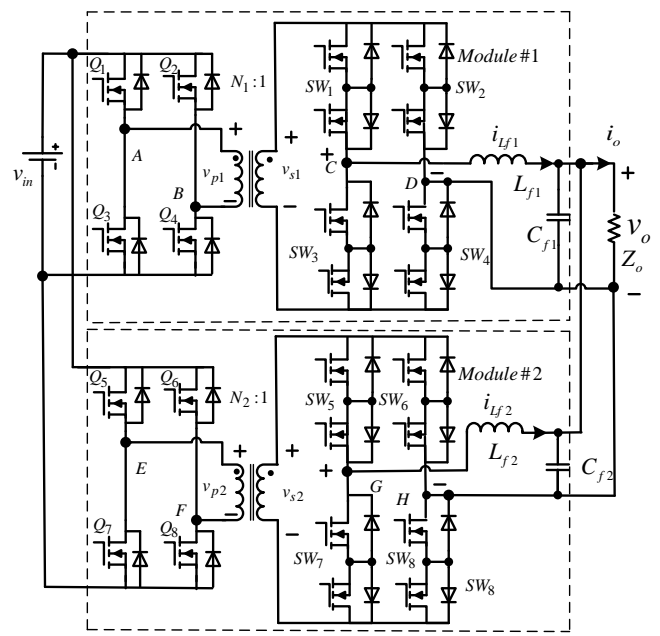

Fig. 1. Parallel connected two HF AC link inverters.

instantaneous average-current-sharing scheme is employed to share the load current evenly, but the currents through the output inductors and capacitors have to be sensed at the same time [4] , which complicates the control design.

At present, the most widely used methods for regulating the output current for paralleled inverters include the ramp comparison and hysteresis control strategies. With the ramp comparison current control using a proportional integral (PI) regulator, accurate current tracking for individual modules cannot be obtained [3], [4], [9]. The hysteresis current control exhibits advantages such as simple implementation, robustness and high dynamic capability [5], [12], [13]. However, the switching frequency varies and the output filter is difficult to design. The predictive control strategy offers the potential for achieving more precise current control with minimal distortion and harmonic noises [14]. Although it has been used extensively for single inverters, it has seldom been used for parallel connected inverters.

Parallel connected HF AC link inverter modules are presented in this paper. To achieve output current sharing and to suppress circulating currents, a three-loop control scheme consisting of a common output voltage loop, individual circulating current suppressing (CCS) loops and inner current tracking (ICT) loops, is introduced. To improve the current tracking accuracy, each of the ICT loops is implemented by predictive current control. In addition, a DSP controller can generate all of the required PWM signals for the system, which aids in simplifying the design.

This paper is organized as follows. The operation principle of the control strategy is analyzed in section II. Simulations and the loop gain design are carried out in section III. A 200W prototype is fabricated and experimentally evaluated in section 4 . Some conclusions are given in section $\mathrm{V}$.

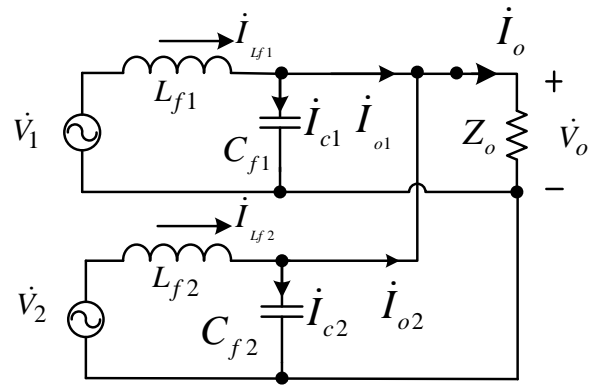

Fig. 2. Diagram of paralleled two inverter modules.

\section{PRoposed Digital Control StRATEgy}

\section{A. Main Circuit and Circulating Current Analysis}

A parallel connection composed of two HF AC link inverters is taken as an example to illustrate the detailed connection, which can be seen in Fig.1. Each inverter module in this figure consists of a full-bridge inverter, a $\mathrm{HF}$ transformer, a full-bridge cycloconverter and an output low pass LC filter. Each switch of the cycloconverter is composed of two N-channel MOSFETs connected with a common source and therefore both of the MOSFETs of one bi-directional switch can share the same gate signal.

For ideal operation of the paralleled connected two HF AC link inverters, the circulation currents flowing among the inverter modules instead of the load should be zero. To understand the circulating currents, an equivalent circuit from the output side can be seen in Fig.2.

In Fig.2, $\dot{V}_{1}$ and $\dot{V}_{2}$ represent the output fundamental voltages of the two individual inverters. For the sake of simplicity, it is assumed that $L_{f 1}=L_{f 2}=L_{f}$ and $C_{f 1}=C_{f 2}=C_{f}$.

According to this figure, for the arbitrary module \#i, the following is obtained:

$$
\begin{gathered}
\left.\dot{V}_{i}\right|_{i \in[1,2]}=j \omega L_{f} \cdot \dot{I}_{L f i}+\dot{V}_{o} \\
\left.\dot{I}_{L f i}\right|_{i \in[1,2]}=j \omega C_{f} \cdot \dot{V}_{o}+\dot{I}_{o i}
\end{gathered}
$$

where $\omega$ is the fundamental angular frequency of the output voltage.

According to (1), the difference between the two output inductor currents can be expressed as:

$$
\dot{I}_{L f 2}-\dot{I}_{L f 1}=\frac{\dot{V}_{2}-\dot{V}_{1}}{j \omega L_{f}}
$$

Based on (2), the following can be obtained: 


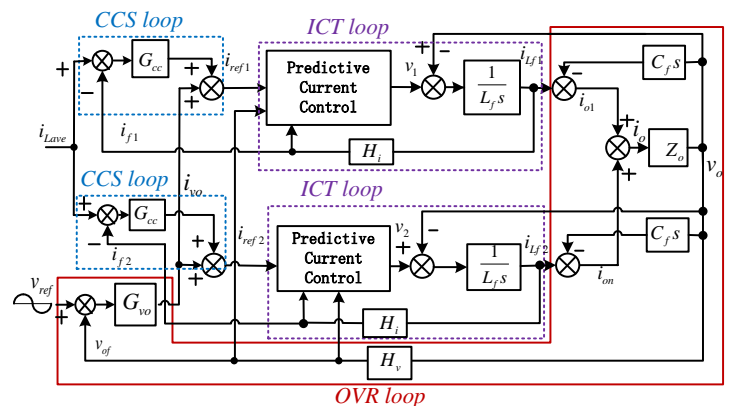

Fig. 3. Proposed control strategy.

$$
\dot{I}_{L f a v e}=\frac{\dot{I}_{L f 2}+\dot{I}_{L f 1}}{2}=j \omega C_{f} \cdot \dot{V}_{o}+\frac{\dot{I}_{o 2}+\dot{I}_{o 1}}{2}
$$

since:

$$
\dot{I}_{o 1}+\dot{I}_{o 2}=\dot{I}_{o}=\frac{\dot{V}_{o}}{Z_{o}}
$$

Substituting (5) into (4) yields:

$\dot{I}_{\text {Lfave }}=\frac{\dot{I}_{L f 2}+\dot{I}_{L f 1}}{2}=j \omega C_{f} \cdot \dot{V}_{o}+\frac{\dot{V}_{o}}{2 Z_{o}}$

According to (4) and (6), the following can be obtained:

$$
\left\{\begin{array}{l}
\dot{I}_{L f 2}=\frac{\dot{V}_{2}-\dot{V}_{1}}{2 j \omega L_{f}}+\dot{I}_{\text {Lfave }} \\
\dot{I}_{L f 1}=\frac{\dot{V}_{1}-\dot{V}_{2}}{2 j \omega L_{f}}+\dot{I}_{\text {Lfave }}
\end{array}\right.
$$

As illustrated in (7), each inductor current contains three parts. The first part is the circulating current and the other two parts just equal the average value of the two output inductor currents. Therefore, it can be concluded that for the arbitrary module, if its inductor current equals the average value of all the inductor currents, then the circulation current is zero.

\section{B. General Control Strategy}

The general control strategy for the system is shown in Fig.3. For the closed-loop control of each inverter module of DC-AC inverters, it is composed of three loops, i.e., an OVR regulation loop, individual CCS loops and individual ICT loops, which have been denoted by different rectangle regions. The sum of the individual CCS loop outputs and the output of the common OVR loop works as a reference for the individual ICT loops. As seen in the figure, $v_{\text {ref }}$ is the sinusoidal voltage reference, $v_{O}$ is the output voltage, $v_{o f}$ is the output voltage feedback, while $i_{L f 1}$ and $i_{L f 2}$ are the output inductor currents of the two inverter modules respectively. $i_{o}$ is the output current, $H_{i}$ represents the current gain and $H_{v}$ is the feedback voltage gain. The variable $i_{\text {Lave }}$ is

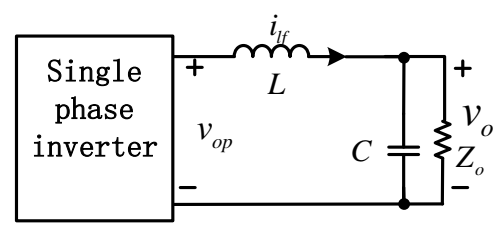

Fig. 4. Schematic of a single-phase inverter.

the average value of the two inductor current feedback signals, working as the reference for all of the circulating current suppression loops, which is as follows:

$$
i_{\text {Lave }}=H_{i} \cdot \frac{\left(i_{L f 1}+i_{L f 2}\right)}{2}
$$

The CCS loop can suppress the circulating currents due to parameter mismatches of the modules and perturbations. As seen from (7), once the individual output currents can track the average of the two output inductor currents with high accuracy, there are no longer any circulating currents. $G_{v o}$ and $G_{c c}$ are the compensation networks for the common OVR loop and the individual CCS loop, respectively. $G_{v o}$ and $G_{c c}$ are the compensation networks for the common OVR loop and the individual CCS loop, respectively. Both $G_{v o}$ and $G_{c c}$ are PI controllers which can achieve zero error tracking. For these PI regulators, the inner current control loop cannot achieve zero error tracking. Therefore, a PI controller as an inner current controller cannot obtain precise current control and transient circulating currents may occur.

However, with a predictive current controller for the ICT loop, the actual inductor current can track the reference current with high precision. The operation principle of the predictive current control can be explained as follows.

A simplified schematic for a single-phase inverter is shown in Fig.4. For the output voltage, a linear extrapolation can be used, thus the following is obtained:

$$
v_{o}(n+1)=2 v_{o}(n)-v_{o}(n-1)
$$

where $[\mathrm{n}+1],[\mathrm{n}]$ and $[\mathrm{n}-1]$ are three adjacent sampling points. Assume that the change of the output voltage over one sampling period is linear. Thus the average value of the output voltage over a sampling period [n, $n+1]$ can be expressed as:

$$
v_{\text {oav }}(n)=\frac{v_{O}(n+1)+v_{o}(n)}{2}
$$

Substituting (9) into (10) gives:

$$
v_{\text {oav }}(n)=\frac{3 v_{o}(n)-v_{o}(n-1)}{2}
$$


In the same way, to get (9), the output voltage at the sampling $\mathrm{n}$ can be written as:

$$
v_{o}(n)=2 v_{o}(n-1)-v_{o}(n-2)
$$

Substituting (11) into (12) leads to:

$$
v_{\text {oav }}(n)=\frac{5}{2} v_{o}(n-1)-\frac{3}{2} v_{o}(n-2)
$$

The inverter inductor current is decided by the following differential equation:

$$
v_{o p}=v_{o}+L \frac{d i_{l f}}{d t}
$$

Because the inverter is operated with a fixed switching frequency, the sampling period is constant with the value of $\triangle T$. In the switching period [ $n, n+1]$, (14) can be written in a discrete form:

$$
v_{\text {opav }}(n)=v_{\text {oav }}(n)+L \frac{i_{\text {lf }}(n+1)-i_{\text {lf }}(n)}{\Delta T}
$$

The target of the controller is making the output current equal to the reference current value at the sampling point $[n+1]$. Thus the following is obtained:

$$
i_{\text {lf }}(n+1)=i_{\text {ref }}(n+1)
$$

The substitution of (16) into (15) results in:

$$
v_{\text {opav }}(n)=v_{\text {oav }}(n)+L \frac{i_{\text {ref }}(n+1)-i_{\text {load }}(n)}{\Delta T}
$$

In the same way, to get (14), the output inductor current at the sampling point $\mathrm{n}$ can be expressed as:

$$
i_{\text {lf }}(n)=i_{\text {lf }}(n-1)+\frac{\Delta T}{L}\left(v_{\text {opav }}(n-1)-v_{\text {oav }}(n-1)\right)
$$

The substitution of (13) into (15) gives:

$$
v_{\text {opav }}(n)=\frac{5 v_{O}(n-1)-3 v_{o}(n-2)}{2}+L \frac{i_{l f}(n+1)-i_{l f}(n)}{\Delta T}
$$

By substituting (18) into (19), the demand average output voltage applied in the switching period $[n-1, n]$ is:

$$
\begin{aligned}
& v_{\text {opav }}(n)=4 v_{o}(n-1)-2 v_{o}(n-2+) \\
& L \frac{i_{\text {ref }}(n+1)-i_{l f}(n-1)}{\Delta T}-v_{\text {opav }}(n-1)
\end{aligned}
$$

\section{Digital PWM Generation and Commutation}

A DSP TMS320F2407 is selected to implement the PWM generation and the closed loop control. Although the discrete values of the average value of the inverter output voltage are obtained at each sampling point, these discrete value constants can be viewed during one sampling interval and they work as the sampling values of the modulation waveform $v_{\text {opav }}$. The carrier waveform in a digital control system is accomplished by the general purpose (GP) timer 1 , working in the up/down counting mode which can simulate a

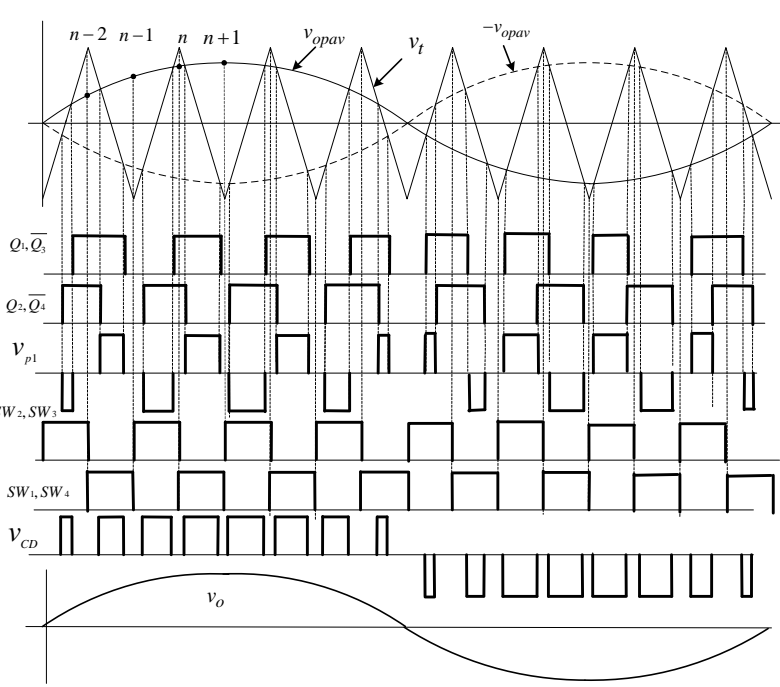

Fig. 5. Schematic of digital PWM generation.

symmetrical triangular waveform. The negative value of $v_{\text {opav }}$ works as another modulation waveform.

To improve the conversion efficiency, the primary HF inverters are controlled with digital phase-shifted (PS) PWM. The detailed PS-PWM generation method can be seen in reference [6].

As can be seen from Fig.5, the PWM gate signals for the cycloconverter switches are kept unchanged while the phase shifted angle for the inverter switches varies according to the modulation. Based on these gate signals, a uniploar SPWM waveform can be obtained from the HF AC link inverter output. A nearly pure sinusoidal waveform can be obtained with a low pass LC filter. The way to generate the PWM gate signals for module \#2 is the same as that for module \#1. Note that the two cycloconverter switches share the same gate signals. This implies that $\mathrm{SW}_{1}, \mathrm{SW}_{4}, \mathrm{SW}_{5}$ and $\mathrm{SW}_{8}$ are gated with the same signal while the remaining ones $\mathrm{SW}_{2}$, $\mathrm{SW}_{3}, \mathrm{SW}_{6}$ and $\mathrm{SW}_{7}$ are gated with another signal.

Without a loss of generality, assuming $v_{C D}>0, i_{L f 1}<0$, there are eight operational modes in one switching period. The corresponding equivalent circuits are shown in Fig.6.

Detailed discussion for each of the working modes are neglected. During all of the modes, it should be noted that the inductor current commutates between the two legs of the cylconverter. The gating signals of the two legs are overlapped during the commutation. Before the commutation, this is shown in (f). During the commutation, as illustrated in (9), in this mode, the two legs conduct. The working mode is transferred to (h) when the commutation process is completed. 


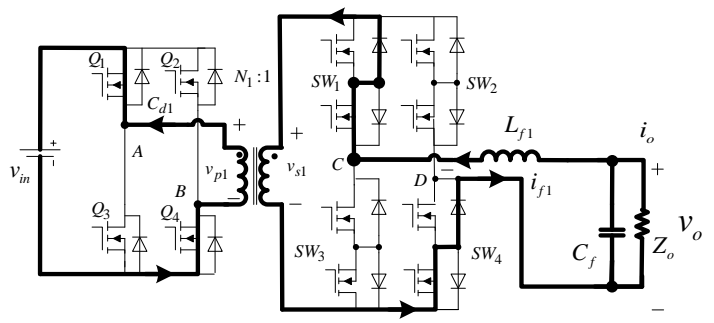

(a)

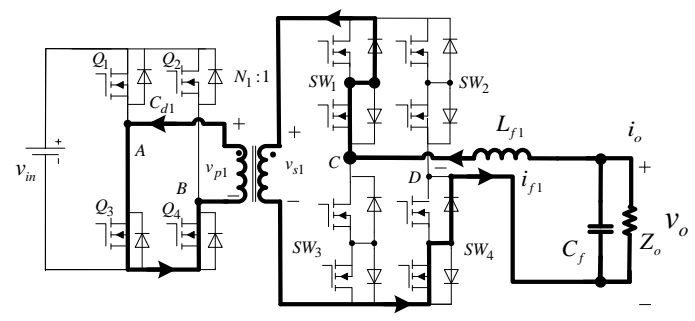

(b)

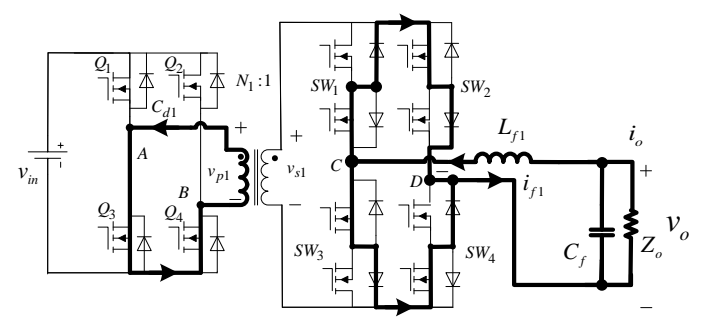

(c)

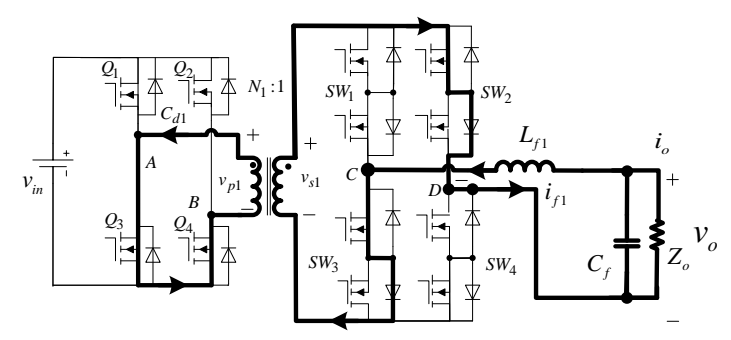

(d)

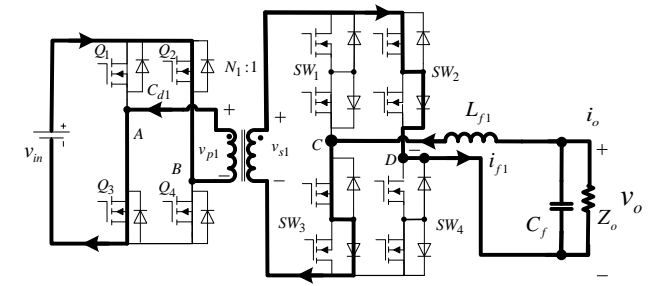

(e)

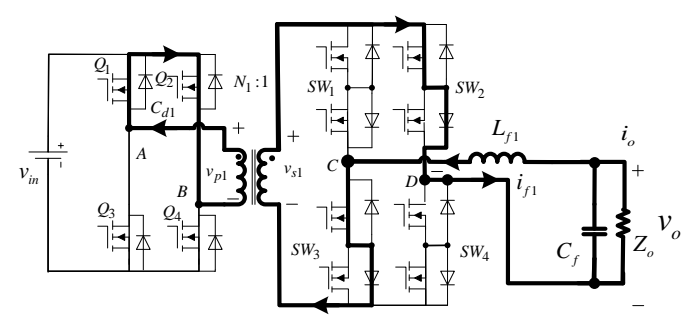

(f)

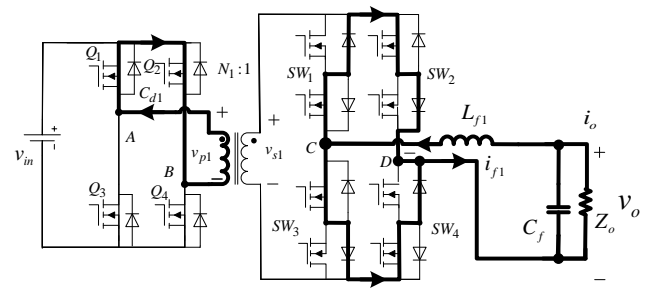

(g)

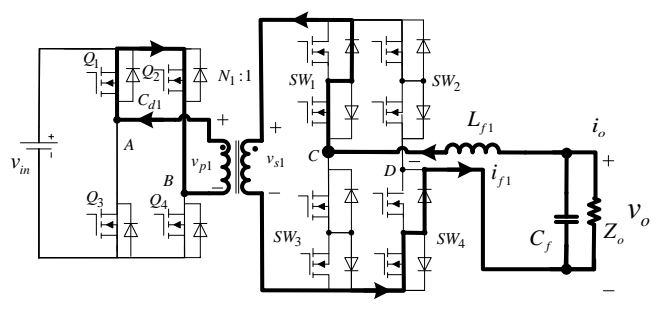

(h)

Fig. 6. Operational stages for energy return.

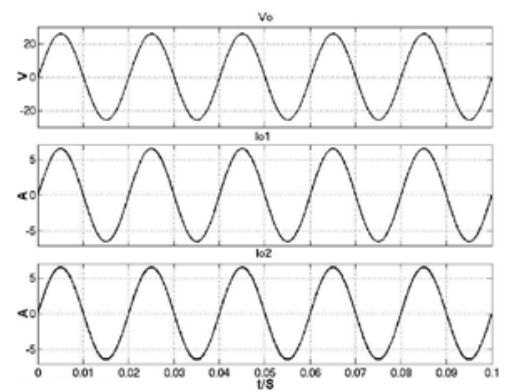

Fig. 7. Steady state output voltage and output currents.

TABLE I

SYSTEM SPECIFICATIONS

\begin{tabular}{|c|l|c|l|}
\hline Item & Value & Item & Value \\
\hline$v_{\text {in }}$ & $80 \mathrm{~V}$ & $R_{O}$ & $2 \Omega$ \\
\hline$v_{o}$ & $20 \mathrm{~V}$ & $f_{s}$ & $10 \mathrm{kHz}$ \\
\hline$f_{o}$ & $50 \mathrm{~Hz}$ & $C_{f}$ & $10 \mu \mathrm{F}$ \\
\hline $\mathrm{N}_{1}: 1$ & $2.5: 1$ & $C_{d 1}, C_{d 2}$ & $2 \mu \mathrm{F}$ \\
\hline $\mathrm{N}_{2}: 1$ & $2: 1$ & $L_{f 1}=L_{f 2}$ & 850 \\
& & & $\mu H$ \\
\hline$f_{s}$ & $10 \mathrm{KHz}$ & $\triangle T$ & $50 \mu \mathrm{s}$ \\
\hline
\end{tabular}

\section{SimUlation AND LOOP GAIN DESIGN}

In this section, a MATLAB/Simulink model for the parallel connection of two HF AC link inverter modules is developed to verify the proposed digital control system. The specific simulation parameters are shown in Table I. It should be noted that the turns ratios of the two HF transformers are intentionally selected to be different. The turns ratio of transformer $T_{1}$ is $2.5: 1$, while the turns ratio of $\mathrm{T}_{2}$ is $2: 1$.

With the system specifications shown in the Table I, the 


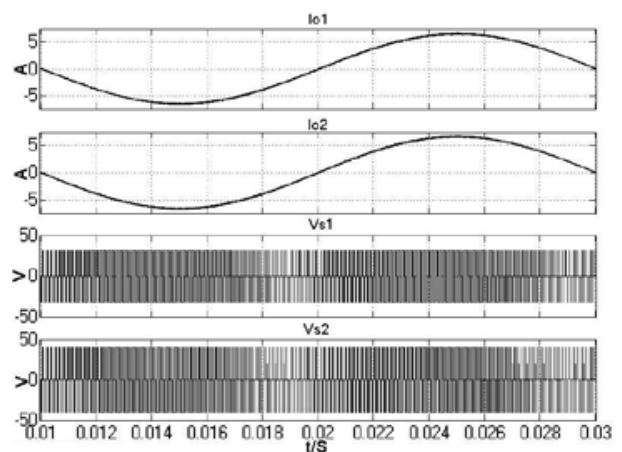

Fig. 8. Secondary voltages of HF transformers.
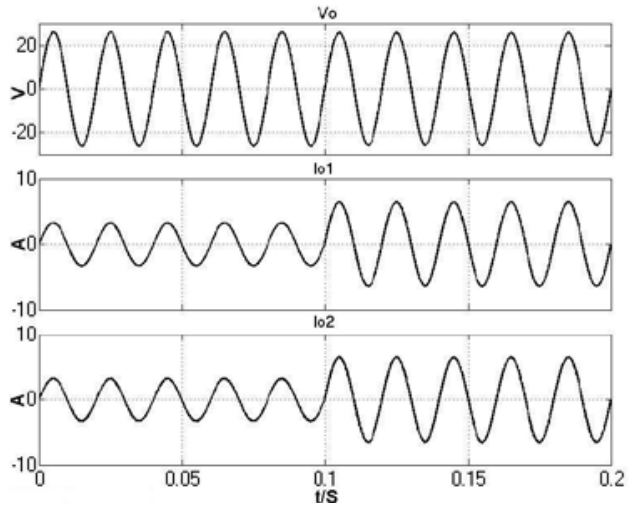

Fig. 9. Transient response from half load to full load.

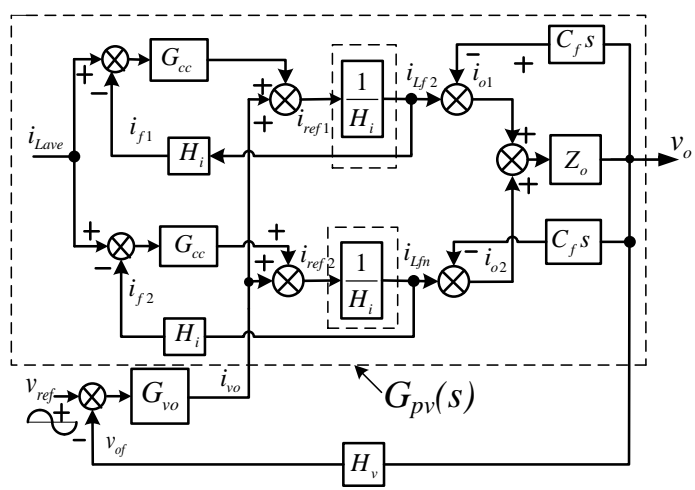

Fig. 10. Simplified control strategy.

simulation results are displayed in Fig.7 to Fig.9. Fig.7 shows the output voltage and the individual output currents at the steady state. As can be seen, with proposed digital control strategy, excellent output current sharing can be achieved between the two inverter modules. Fig.8 shows the output secondary voltages of the individual HF transformers. Despite the different amplitudes of the HF AC voltages due to turns ratio mismatches, both of the output currents have almost the same instantaneous values. Fig.9 shows the response of the output voltage and the individual output currents corresponding to a load stepping from a half load (5A) to a full load (10A). As can be seen, despite the presence of transients, the load current can be shared equally while the output voltage is kept almost unchanged.

Since predicative current control can achieve zero error tracking, for the two modules, the following can be obtained:

$$
i_{L f j}=\frac{1}{H_{i}} i_{r e f j}
$$

Therefore, the predicative current control strategy can be view as a proportional unit. Hence the proposed control strategy for two modules can be simplified, as shown in Fig. 10.

According to Fig.10, the expressions of the individual inductor currents can be obtained as follows:

$$
\left\{\begin{array}{l}
i_{L f 1}=\left(i_{v o}+G_{C C}\left(i_{\text {Lave }}-H_{i} \cdot i_{L f 1}\right)\right) \frac{1}{H_{i}} \\
i_{L f 2}=\left(i_{v o}+G_{C C}\left(i_{\text {Lave }}-H_{i} \cdot i_{L f 2}\right)\right) \frac{1}{H_{i}}
\end{array}\right.
$$

Summing up the two equations of (22), the following is obtained:

$$
\begin{aligned}
& i_{L f 1}+i_{L f 2}= \\
& \left(2 \cdot i_{v o}+G_{C C}\left(2 \cdot i_{L a v e}-H_{i} \cdot\left(i_{L f 1}+i_{L f 2}\right)\right)\right) \frac{1}{H_{i}}
\end{aligned}
$$

Substituting the two inductor currents from (9) into (23), results in the following:

$$
i_{L f 1}+i_{L f 2}=\frac{2}{H_{i}} i_{v o}
$$

According to the connection shown in Fig.1, the output voltage is:

$$
v_{o}=\left(\frac{1}{2 \cdot s C_{f}} / / Z_{o}\right)\left(i_{L f 1}+i_{L f 2}\right)
$$

Substituting (25) into (24) yields:

$$
G_{p v}(s)=\frac{v_{o}}{i_{v o}}=\left(\frac{1}{2 \cdot s C_{f}} / / Z_{o}\right) \frac{2}{H_{i}}=\frac{\frac{2}{H_{i}} Z_{o}}{2 \cdot s C_{f} Z_{o}+1}
$$

where $G_{p v}(s)$ is the equivalent plant transfer function of the OVR loop. It can be observed from (26) that the transfer function of the output voltage to the OVR output has nothing to do with the CCS loops. This also shows that the OVR loop and the CCS loops are decoupled.

As shown in (26), for a purely resistive load, the control 


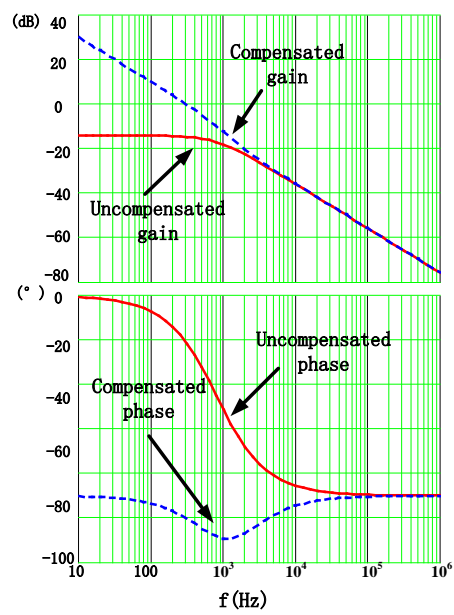

Fig .11. Uncompensated and compensated inverters' loop gains.

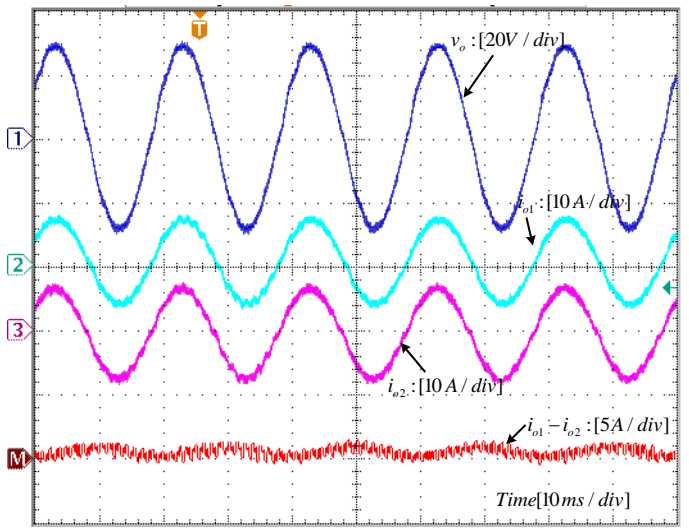

Fig. 12. The output voltage and output currents with the proposed predictive control strategy.

objective of the OVR loop belongs to a type I system. If the compensator is the PI type, the system is sure to be theoretically stable with any proportional and integral coefficients. The loop gain of the OVR loop is given by:

$$
T_{v o}=G_{v o}(s) G_{p v}(s) H_{v}
$$

The loop gain of the OVR loop is shown in Fig.11, where $R_{o}=2 \Omega, C_{f}=10 \mathrm{uF}, H_{i}=0.5, H_{v}=0.05$ and $G_{v o}=1+\left(1 \times 10^{4} / \mathrm{s}\right)$. The switching frequency of the system is $10 \mathrm{kHz}$. As can be seen in Fig.11, the crossover frequency is chosen to be $2 \mathrm{kHz}$, which is one-fifth of the switching frequency. The phase margin is $73^{\circ}$, which is enough for the system to be stable.

\section{EXPERIMENTAL RESULTS}

To verify the proposed digital control strategy, experiments on a prototype with the same parameters as the simulation have been made. The system specifications are shown in Table I. However, it should be noted that to verify the effectiveness of the proposed control scheme in the presence

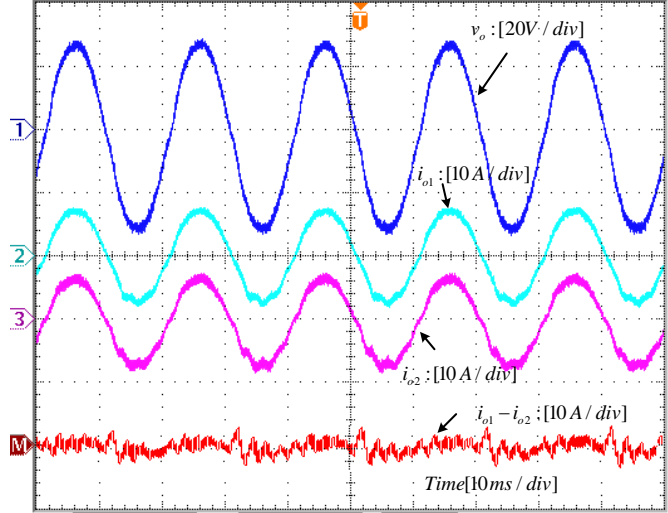

Fig. 13. The output voltage and output currents with conventional ramp comparison based on PI control.

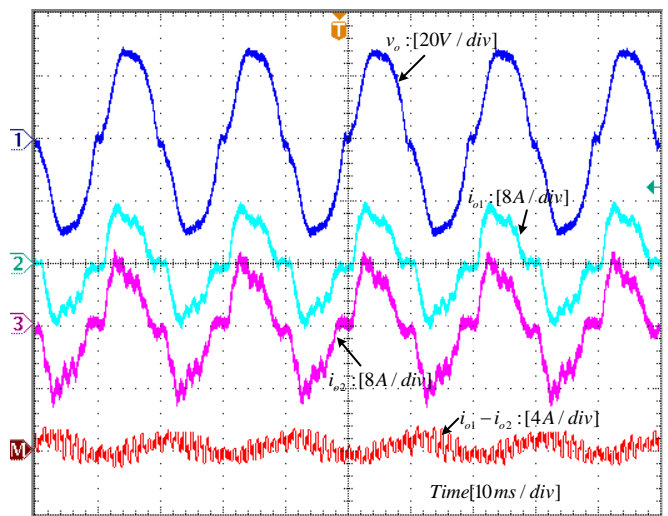

Fig. 14. The output voltage and individual output currents with uncontrolled rectifier load.

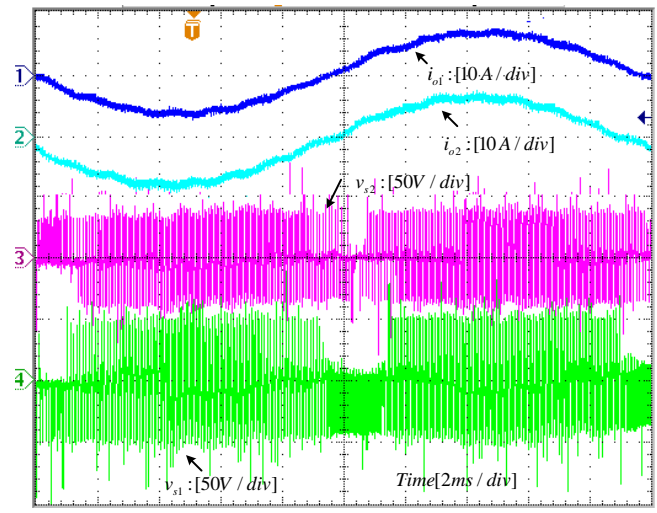

Fig. 15. Secondary voltages of individual HF transformers at steady state.

of mismatches of the converter parameters, the turns ratios of the two power transformers are intentionally designed to be different, as shown in Table I.

Some experimental results are shown in Fig.12 to Fig.17. Fig.12 shows the output voltage and the individual output currents with the proposed predictive current control, while Fig.13 shows the results with the conventional ramp 


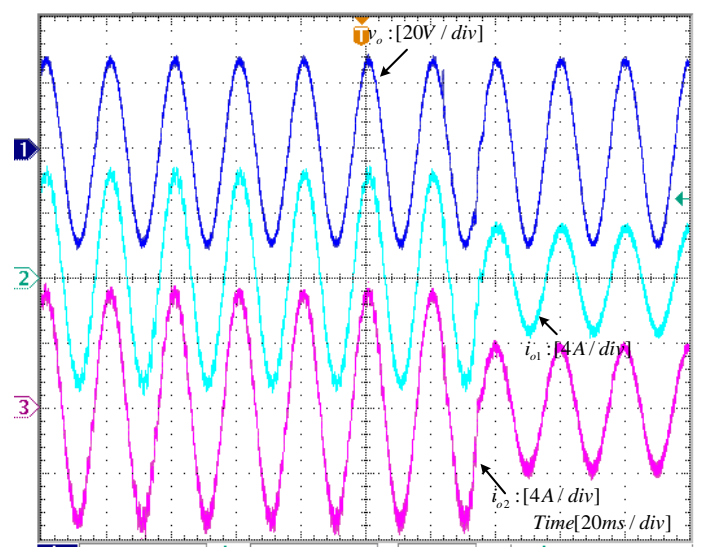

Fig. 16. Response to a load step change from full load to half load.

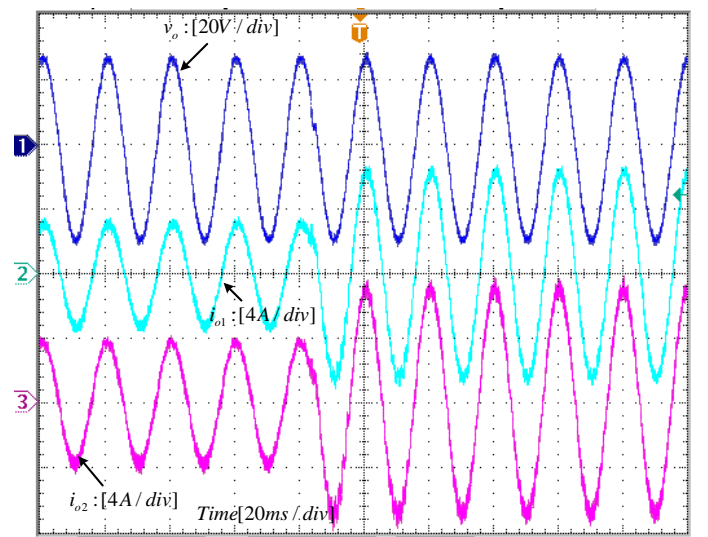

Fig. 17. Response to a load step change from half load to full load.

comparison based on PI control. Although the load current can be shared with the two different current tracking methods, the output currents are less distorted with the proposed control strategy when compared to those of the ramp comparison.

Fig.14 shows the response due to an uncontrolled rectifier load, where the filtering capacitance in parallel with the rated resistive load is $330 \mu \mathrm{F}$. As illustrated, although the output voltage is distorted, equal sharing of the load can be obtained between the two inverter modules.

Fig.15 shows the secondary voltages of the two HF transformers at the rated resistive load. As can be seen, despite the fact that the HF amplitudes of the two secondary voltages are different due to the turns ratio mismatch, both of the two output currents have almost the same instantaneous values.

The dynamic response of the system can be viewed in Fig.16 and Fig.17, in which the input voltages vary corresponding to a load stepping between a half load (5A) and a full load (10A). Despites transients, the load current can be shared equally fairly well.

\section{CONCLUSIONS}

In this paper, parallel connected HF AC link inverter modules are discussed. The proposed control strategy is composed of three control loops, i.e., a common OVR regulation loop, individual CCS loops and individual ICT loops. To achieve accurate tracking for the ICT loops, a predictive current controller is used. The proposed control strategy and all of the generated PWM signals are implemented by one DSP.

The effectiveness of the proposed digital control strategy is verified through simulations. To further validate its effectiveness, a 200W prototype composed of two HF AC link inverter modules is fabricated and tested. With this scheme, excellent sharing of the output current can be obtained during steady state as well as transients in spite of mismatches in the module parameters. In addition, when compared with the conventional ramp comparison employing PI control, the current tracking precision is improved.

\section{ACKNOWLEDGMENT}

This work was supported by National Nature Science Foundation of China ( Grant No.50807005), Excellent Young Scholars Research Fund of Beijing Institute of Technology (2010YC0604), Key Laboratory of Complex System Intelligent Control and Decision (Beijing Institute of Technology), Ministry of Education and State Key Laboratory of Advanced Welding and Joining(Grant No. AWPT-M03-2010)

\section{REFERENCES}

[1] T. Yokoyama, N. Doi, T. Ishioka, "Verification of an autonomous decentralized UPS system with fast transient response using a FPGA-Based hardware controller," Journal of Power Electronics, Vol. 9, No. 5, pp. 507 -515, Sep. 2009.

[2] C. L. Chen, Y. B. Wang, J. S. Lai, Y. S. Lee, and D. Martin, "Design of parallel inverters for smooth mode transfer micogrid applications," IEEE Trans. Power Electron., Vol. 25, No. 1, pp. 6-15, Jan. 2010.

[3] T. F. Wu, Y. E. Wu, H. M. Hsieh, and Y.K. Chen "Current weighting distribution control strategy for multi-inverter systems to achieve current sharing," IEEE Trans. Power Electron., Vol. 22, No. 1, pp. 160-168, Jan. 2007.

[4] X. Sun, Y. S. Lee, and D. H. Xu, "Modelling, analysis, and implementation of parallel multi-inverter systems with instantaneous average-current sharing sheme,” IEEE Trans. Power Electron., Vol. 18, No. 3, pp. 844-856, May 2003.

[5] D. Sha, Z. Guo, and X. Liao, "Control strategy for inputparallel-output-parallel connected high-frequency isolated inverter modules,” IEEE Trans. Power Electron., Vol. 26, No. 8, pp. 2237-2248, Aug. 2011.

[6] Z. Salam, "Bidirectional high-frequency link inverter with deadbeat control,” Journal of Power Electronics, Vol. 9, No. 5, pp.726 -735, Sep. 2009.

[7] P. T. Krein , R. S. Balog, and X. Geng, "High- frequency link inverter for fuel cells based on multiple-carrier 
PWM,” IEEE Trans. Power Electron., Vol. 19, No. 5, pp.1279-1288. Sep. 2004.

[8] D. Sha, Y. Bao, B. Qin, "Full digitalized ZVZCS control strategy for high frequency link inverter," in Pro. PESC, pp. 2746-2749, 2006.

[9] H. Cai, R. X. Zhao, and H. Yang, "Study on ideal operation status of parallel inverters," IEEE Trans. Power Electron., Vol. 23, No. 6, pp. 2964 -2969, Nov. 2008.

[10] J.-W. Kim, H.-S. Choi, and B.-H. Cho, "A novel droop method for converter parallel operation," IEEE Trans. Power Electron., Vol. 17, No. 1, pp. 25-32, Jan. 2002.

[11] W. C. Lee, T. K. Lee, S. H. Lee, K. H. Kim, D. S. Hyun, and I. Y. Suh, "A master and slave control strategy for parallel operation of three-phase UPS systems with different reatings," IEEE Trans. Power Electron., Vol. 17, No. 1, pp. 25-32, Jan. 2002.

[12] A. Shukla, A.Ghosh, and A. Joshi, "Improved multilevel hysteresis current regulation and capacitor voltage balancing schemes for flying capacitor multilevel inverter voltage and frequency droop control method for parallel inverters,” IEEE Trans. Power Electron., Vol. 23, No. 2, pp. 518-529, Mar. 2008.

[13] L. Dalessandro, S. D. Round, and J. W. Kolar, "Center-point voltage balancing of hysteresis current controlled three-level PWM rectifiers," IEEE Trans. Power Electron., Vol. 23, No. 5, pp. 2477-2488, Sep. 2008.

[14] H. M. Kojabadi, B. Yu, I. A.Gadoura, L. Chang and M. Ghribi, "A novel DSP-based current controlled PWM strategy for single phase grid connected inverters," IEEE Trans. Power Electron., Vol. 21,No. 4, pp. 985-993, Jul. 2006.

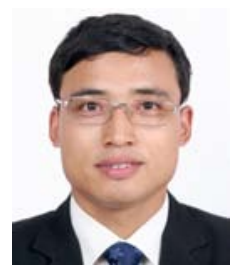

Deshang Sha was born in 1977. He received his B.S. from the Luoyang Institute of Technology, Luoyang, China, in 1998, his M.S. from the Nanjing University of Aeronautics and Astronautics, Nanjing, China, in 2001, and his Ph.D. from the Institute of Electrical Engineering, Chinese Academy of Sciences, Beijing, China, in 2005, all in Electrical Engineering. From 2005 to 2007, he worked as the Head and Chief Engineer of the full-digitalized welding machine research team of the Time Group Company. Since 2008, he has been with the School of Automation, Beijing Institute of Technology (BIT), Beijing, China, where he is currently an Associate Professor. He was selected as one of the Excellent Yong Scholars at BIT in 2010. His current research interests include high frequency power converters, digital control of power electronics and renewable energy power generation systems.

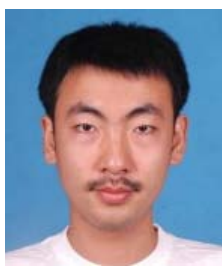

Zhiqiang Guo was born in 1985 . He received his B.S. from the Hebei University of Technology, Tianjin, China, in 2008, and his M.S. from the Beijing Institute of Technology (BIT), Bejing, China, in 2010, both in Automation. He is now pursing his Ph.D. in Electrical Automation at the Beijing Institute of Technology (BIT). His current research interests include the modeling and control of power electronics converters.

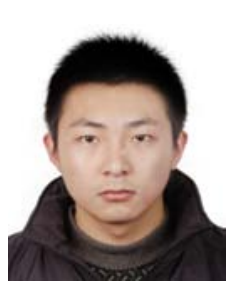

Kai Deng was born in 1986. He received his B.S. from the Nanjing Agricultural University, Nanjing, China, in 2008, and his M.S. from the Beijing Institute of Technology (BIT), Beijing, China, in 2011, both in Electrical Engineering. He is now pursing his Ph.D. in Electrical Engineering at the South East University, Nanjing, China. His current research interests include the digital control of power converters and system integration of modular power converters.

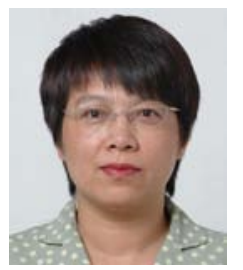

Xiaozhong Liao was born in China, in 1962. She received her B.S. and M.S. in Electrical Engineering from Tianjin University, Tianjin, China, in 1982 and 1984, respectively, and her Ph.D. in Control Sciences and Engineering from the Beijing Institute of Technology (BIT), Beijing, China, in 2004. She was a Visitor Researcher in the Department of Electrical and Electronic Engineering, University of Central Lancashire, Preston, U.K., form 1995 to 1996. She is now an Associate Dean and a Full Professor in the School of Automation, Beijing Institute of Technology. Her current research interests include power electronics, motor drives and renewable energy power conversion. 